\title{
Revistas de teatro em diálogo peninsular
}

\section{Sebastiana Fadda}

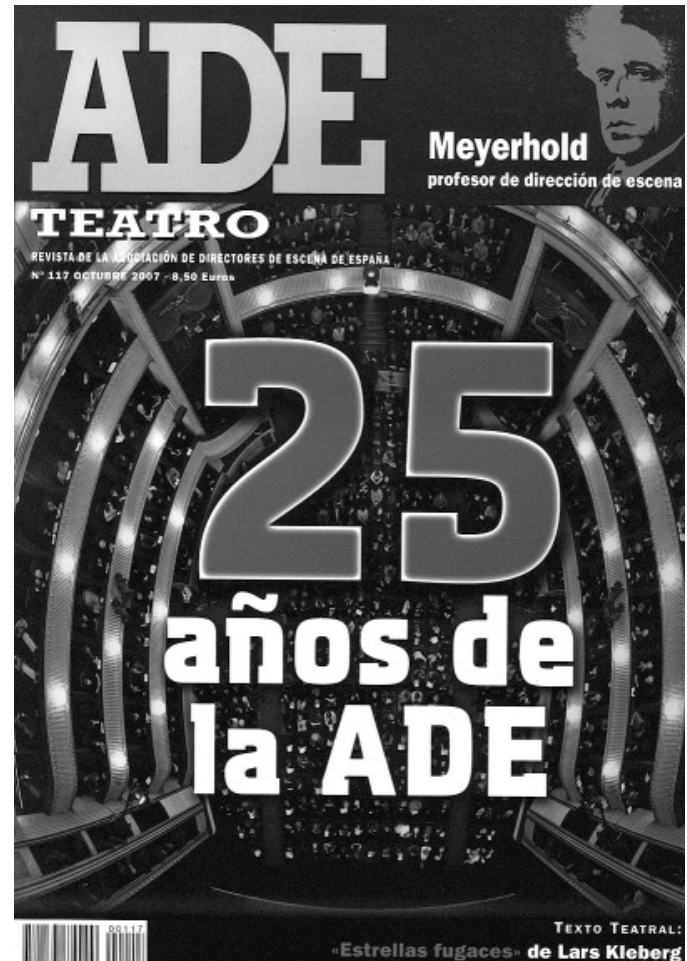

Situada em frente de Vigo, na outra margem da ria, Cangas do Morrazo está inserida numa paisagem verdejante e de sinuosidades generosas, que se alongam para as águas onde antigamente os habitantes procuravam o seu sustento. Sossegada e acolhedora, a vila tornou-se apelativa pelos roteiros turísticos e pelas propostas culturais que soube activar e desenvolver.

Entre estas últimas, é de assinalar a Mostra Internacional de Teatro Cómico e Festivo, que em 2008 festejou a sua XXV edição, tornando-se no mais antigo festival de teatro galego. De 3 a 12 de Julho, vários grupos de teatro cómico, circense, de títeres e de rua, profissionais e amadores, animaram palcos, espaços alternativos, praças e ruas, contando com a adesão dum público numeroso e noctívago. Houve ainda oficinas, música e lançamentos editoriais. Paralelamente, decorreram

também as $\vee$ Xornadas de Mulheres nas Artes Escénicas e o I Encontro lbérico de Revistas de Teatro, sendo este co-promovido em colaboração com a Revista Galega de Teatro.

Ao longo de dois dias, a 6 e 7, os representantes de revistas ibéricas de teatro puderam conhecer as especificidades das várias publicações, ficando evidente a diversidade e dinamismo que marcam o contexto espanhol neste sector.

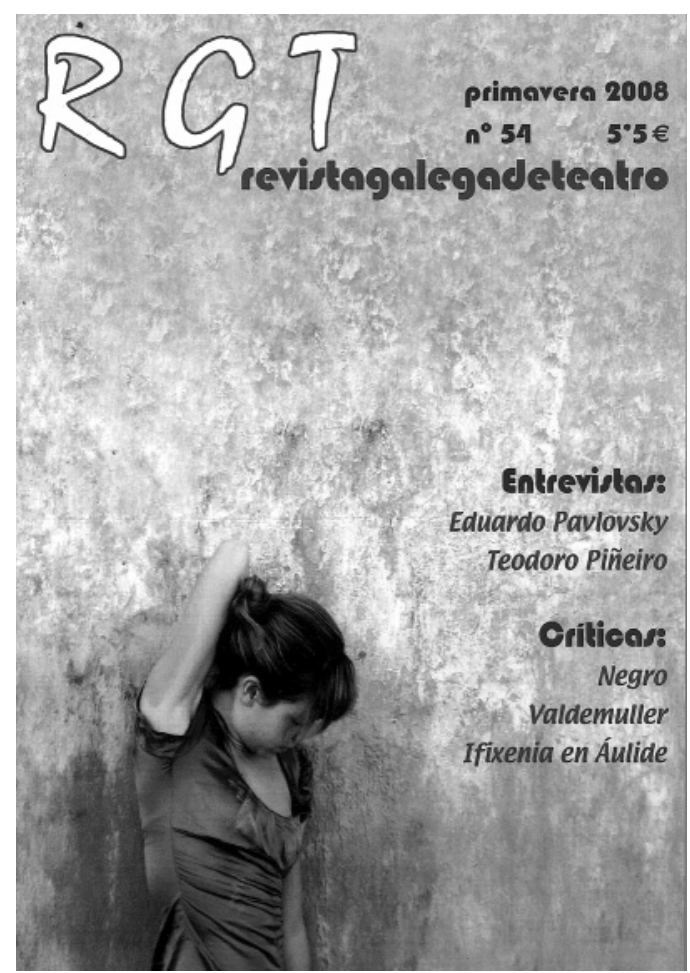

0 programa foi respeitado quase na íntegra e, no primeiro dia, a sessão foi aberta com as palavras de boas-vindas de Antón Lamapereira, em representação das entidades organizadoras, e de Mercedes Giráldez, da Concelleira de Turismo de Cangas. Seguiram-se as comunicações de: António Augusto Barros (Cenalusófona), sobre o panorama editorial das revistas de teatro em língua portuguesa; Karl Svensson (Assaig de Teatre), que teceu algumas considerações sobre a revista teatral entendida como instrumento de diplomacia cultural; Roberto Corte ( $L a$ Ratonera), que falou sobre o leque variegado e plural das revistas teatrais espanholas; Manuel F. Vieites $(A D E)$, que problematizou, de forma articulada e abrangente, várias questões inerentes aos estudos teatrais; Roberto Pascual (Revista Galega de Teatro), que se debruçou sobre a crítica teatral nas revistas da especialidade; Vicente Montoto (Escaramuza), que articulou o seu discurso ponderando e devolvendo perspectivas de profissionais de teatro galego; Joseba Gorostiza (ARTEZ), que ilustrou as possibilidades inovadoras do espaço cibernético em matéria de reflexão e informação sobre as artes cénicas; Isaac Ferreira (Casahamlet), que discorreu sobre as várias matérias que interessam a uma produtora e editora de teatro, tais como criação, documentação e investigação. Na impossibilidade de Javier Rodríguez (Artemad, El Pateo) estar presente, a 
sua comunicação sobre ligações entre entidades de produção teatral e imprensa foi lida por Antón Lamapereira. No dia seguinte, para além de Antón Lamapereira que, desta vez, tomou a palavra pelo Fondo Teatral Maria Casares criado na Biblioteca Pública de Cangas, Adolfo Simón (pela madrilena Primer Acto) e a autora deste relato (pela Sinais de cena), apresentaram depoimentos sobre as revistas em que colaboram e de que foram porta-vozes. Extra programa, pela Revista Galega de Teatro, tomou a palavra também Afonso Becerra. Uma visita à Biblioteca Pública, um breve encontro com a imprensa e uma troca de ideias entre os participantes, sob a forma de balanço e avaliação das possibilidades de estabelecer intercâmbios produtivos, dando continuidade ao Encontro, encerraram os trabalhos. Mas houve ainda a possibilidade de assistir ao espectáculo O grande criador, uma produção irreverente e conseguida do Chapitô baseada numa releitura heterodoxa do livro bíblico do Génesis, podendo ainda acompanhar Revoltallo en pedra 2008, espécie de peregrinação entre artes e arquitecturas locais guiada por gigantones e cabeçudos, com paragens para se desfrutar de teatro de rua, música, danças folclóricas e étnicas, gerando momentos lúdicos devido ao entusiasmo genuíno dos intérpretes, maioritariamente amadores, e tão contagiantes que os transeuntes se tornavam rapidamente peregrinos curiosos e participativos deste ritual popular.

Pelo que foi possivel inferir das intervenções dos participantes do Encontro e da consulta das publicações que estiveram disponiveis e em exposição, vale a pena salientar que:

- o meio espanhol resulta muito mais activo e expressivo em comparação com o angusto e instável meio português; - no país vizinho, associações formadas por categorias de profissionais de teatro (como a Asociación de Directores de Escena), centros de investigação académicos (por exemplo a Associació d'Investigació i Experimentació Teatral), entidades de produção e divulgação teatral (onde cabe a entidade Casahamlet), projectos esforçados, de longo e reconhecido trajecto editorial (veja-se a Primer acto), mas também outros profissionais apaixonados, determinados e com espírito de iniciativa, souberam recortar espaços de expressão e reflexão incontestáveis e consistentes, obtendo resultados exímios;

- mesmo em casos de revistas mais recentes, ou mais frágeis do ponto de vista institucional ou económico, os efeitos são visiveis e dignos de respeito, até quando o seu alcance possa ser geograficamente localizado;

- a imprensa tradicional precisa, e com cada vez maior premência, de se apoiar nas possibilidades de multiplicação do seu eco através da web, nem que seja para fins de divulgação ou como complemento e alternativa ao papel impresso;

- o papel impresso continua a manter, pelo menos idealmente, um carácter menos efémero do que a web, não se substituindo o real tangivel ao virtual possivel, obedecendo estes a finalidades diferentes que podem e

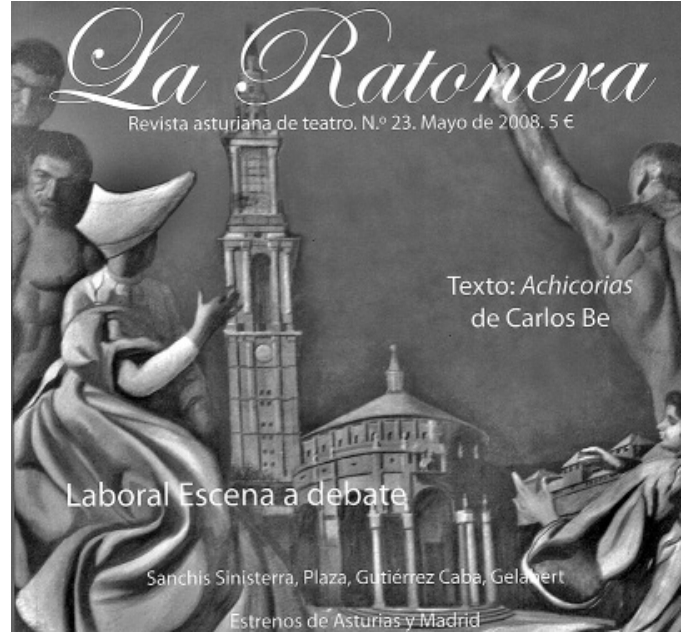

devem encontrar conciliação.

A designação I Encontro lbérico de Revistas de Teatro quis conter a sugestão e o voto de que outras edições se sigam, a fim de se manter aberto o diálogo entre pessoas e instituições que comungam interesses e objectivos, estimulando as perspectivas para troca de colaborações que poderiam efectivar-se a vários niveis. Entre eles, dar a conhecer a existência reciproca, incrementar os respectivos arquivos e fundos de documentação, ampliarse as redes de colaboradores efectivos pelo intercâmbio de textos e artigos que reflictam diferentes saberes, realidades e produções.

Aguardamos expectantes a próxima edição desta iniciativa. Entretanto, para fins de concretização do ponto mais imediatamente viável, segue-se uma lista de contactos das revistas presentes, com as quais se poderá ter uma aproximação on-line ou que poderão ser contactadas por correio electrónico.

\section{Agenda de contactos}

$A D E$ (Asociación de Directores de Escena - Madrid): www.adeteatro.com; redaccion@adeteatro.com

Artez (Revista de las Artes Escénicas - Bilbao e Valladolid): www.artezblai.com; artezblai@artezblai.com

Assaig de Teatre (Associació d'Investigació i Experimentació Teatral - Barcelona): www.aiet.cat; aiet@aiet.cat

Casahamlet (Revista de teatro - A Coruña): imaxescasahamlet.blogspot.com; casahamlet@hotmail.com Setepalcos (Cena Lusófona - Coimbra): www.cenalusofona.pt; teatro@cenalusofona.pt

El Pateo (Artemad, Asociación de Empresas Productoras de Artes Escénicas de la Comunidad de Madrid - Madrid): www.artemad.com; elpateo@hotmail.com

Escaramuza (Asociación de Actores, Directores e Técnicos de Escena de Galicia - Santiago de Compostela): www.aadteg.org; info@aaag.es

La Ratonera (Revista asturiana de teatro - Gijón): www.laratonera.net; e-mail: info@la-ratonera.net

Primer Acto (Cuadernos de investigación teatral - Madrid): www.primeracto.com; primeracto@primeracto.com

Revista Galega de Teatro (Cangas, Pontevedra): www.revistagalegateatro.com; revistagalegateatro@hotmail.com 